\title{
Bilecik İlinde Yaşayan Kadınlarda Spora Katılım, Obezite Prevalansı ve Risk Faktörleri
}

\author{
Raif ZİLELi $\dot{I}^{* *}$ \\ Önder ŞEMŞEK ${ }^{* * *}$ \\ Hüseyin ÖZKAMÇI****
}

Gürkan DİKER ${ }^{* *+* * *}$

Öz

Bu çalışmanın amacı, Bilecik ilinde şehir merkezinde yaşayıp, rekreatif bir etkinlik olarak yürüyüş aktivitelerine katılan kadınlarda obezite prevalansı ve obeziteyi etkileyen risk faktörlerinin araştırılmasıdır.

Çalışmaya Bilecik Şeyh Edebali Stadyumunda rekreasyonel olarak yürüyüş egzersizi yapan, 18-54 yaş

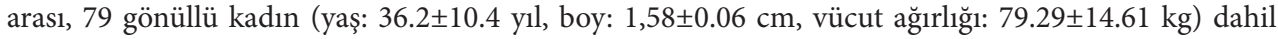
edilmiştir. Katılımcıların boy, vücut ağırlığı, yağ yüzdesi, bazal metabolik hız, bel çevresi, kalça çevresi ölçüldü. Tüm katılımcıların spora katılım, obezite prevelansı ve risk faktörlerini belirlemek amacıyla yüz yüze görüşme yöntemi ile araştırmacılar tarafından epikriz formu doldurmaları sağlandı.

Katılımcıların BKİ ortalaması 31.68 olup, BKİye göre kadınların \% 62'sinde obezite saptandı. Obez kadınların \%40,5'inin ilkokul mezunu, \% 70,9'unun ev hanımı, \%64,6'sının sosyal güvencesi olduğu, \% 84.8' ininspor yapma alışkanlığının olmadığ 1 , \% 94'ünün diyet yapma alışkanlığının olmadığı, \% 51.9'unun sigara tüketmediği, \% 62'sinin alkol tüketmediği, \% 35.4'ünün iki kez doğum yaptığı, \% 35,4 'ünün normal doğum yaptığı, \% 41.8'i düzenli adet olduğu ve \% 53.2'si menopozda olmadığ1 görülmektedir

Obezitenin en sık ilkokul mezunlarında \% 26,6 olduğu, eğitim düzeyi arttıkça obezitenin azaldığı görülmektedir. Obezite görülme sıklığının ev hanımlarında $\% 40,5$ olduğu ve çalışan kadınlarda bu sıklığın azaldığı bulunmuştur. Yine obez kadınların spor yapma alışkanlığının $(\% 54,4)$ ve diyet yapma alışkanlığının (\% 60,8) olmadığı ortaya çıkmıştır. Ayrıca obez kadınların sigara ve alkol tüketme alışkanlıklarının olmadığı, (sırasıyla \% 51.9, \% 62) bulunmuştur. Toplumun en küçük yapı taşını oluşturan ailede, özellikle de kadınlara obezite ile mücadelede eğitim ve egzersiz yapma alışkanlığ 1 kazandırılmasının önemi bir kez daha ortaya çıkmışı̧ır.

Anahtar kelimeler: Obezite, yürüyüş egzersizi, eğitim, ev hanımı

* Bu araştırmanın bir bölümü, 07-09 Kasım 2014 tarihleri arasında 13. Uluslararası Spor Bilimleri Kongresi’nde poster bildiri olarak sunulmuştur.

** Yrd. Doç. Dr., Bilecik Şeyh Edebali Üniversitesi Sağlık Yüksekokulu, raif.zileli@bilecik.edu.tr

*** Yrd. Doç. Dr., Abant İzzet Baysal Üniversitesi Beden Eğitimi ve Spor Yüksekokulu, semsek_o@ibu.edu.tr

**** Öğr. Gör., Dokuz Eylül Üniversitesi Spor Bilimleri ve Teknolojisi Yüksekokulu, hozkamcigumus@deu.edu.tr

***** Arş Gör., Cumhuriyet Üniversitesi Beden Eğitimi ve Spor Yüksekokulu, gdiker@cumhuriyet.edu.tr 


\title{
The Attendance to Sport of Women Living in Bilecik, Obesity Prevalence and Risk Factors
}

\begin{abstract}
The aim of this study is to investigate the risk factors affecting obesity and the obesity prevalence in women who live in the city center of Bilecik and attend to walking events as a recreative activity. 79 voluntary women (age: $36.2 \pm 10.4$ year, height: $1,58 \pm 0.06 \mathrm{~cm}$, weight: $79.29 \pm 14.61 \mathrm{~kg}$ )who exercise at Bilecik Şeyh Edebali Stadium by walking recreational are involved in this study.

The findings are shown as arithmetic mean, standard deviation or percentage with the help of SPSS ("Statistical Package for the Social Sciences") 17,00 packaged software. The mean Body Mass Index of participants is 31.68 . According to BMI, obesity prevalence is $62 \%$ in females. When the variance of obesity according to education level is analyzed, it is seen that $\% 32$ of the women are primary school graduate $(\% 40,5), \% 7$ of them are middle school graduate $(\% 8,9), \% 23$ of them are high school graduate $(\% 29,1), \% 17$ of them are university graduate $(\% 21,5)$. When the variance of obesity according to professional status and social security is analyzed, it is seen that $\% 56$ of the women are housewives $(\% 70,9), \% 23$ of them work in any kind of job $(\% 29,1)$, all the women, who are obese or not, have any kind of social security; social security institution $(\% 64,6)$, retirement fund $(\% 30,4)$, social security organization for artisans and the self-employed $(\% 5,1)$. When the variance of obesity according to the habit of sport or diet is analyzed, it is seen that $\% 84,8$ of the women do not have a habit of exercising, $\% 94$ of them do not have a habit of dieting. It is seen that women who are primary school graduate mostly have obesity with the rate of $\% 26,6$ and when the education level gets higher, the rate of having obesity gets lower. It is found that the rate of being obese among housewives is $\% 40,5$ and this rate becomes less among women who have a job. It has also ensued that obese women do not have a habit of exercising $(\% 54,4)$ and dieting $(\% 60,8)$. The importance of getting women adopt the habit of exercising and the importance of education has come up once again.
\end{abstract}

Keywords: Education, Housewife, Obesity, Walking

\section{GíRiş}

Dünya Sağlık Örgütü (DSO) tarafından obezite, “yağ dokusunun, sağlıkla ilgili olumsuz sonuçlara yol açacak ölçüde artması” olarak tanımlanmaktadır (Çayır ve ark., 2011). Obeziteyi önemli yapan neden, hem bağımsız olarak hem de diğer hastalıklarla birlikte birçok hastalığa neden olması veya bunları alevlendirmesidir (Koruk ve Şahin, 2005).

Obezite, başta Amerika Birleşik Devletleri ve Avrupa olmak üzere tüm dünyada giderek artan ve son 10 yılda prevalansı önceki yıllara göre neredeyse 2 kat artan ciddi bir sağlık sorunu haline gelmiştir (Aydın ve ark., 2012). Türkiye’de obezite prevalansı gelişmiş batılı ülkelerden aşağı kalmamakta, özellikle kadınlarda \% 30 gibi belirgin yüksek oranlara ulaşmaktadır(Nazlıcan ve ark., 2011).

Yetişkinlerde obezite ve sedanter yaşam tarzı biyolojik değişimler ve fiziksel bozulmalarla ilişkilidir 
(Anton ve ark, 2011). Özellikle orta yaş veüzeri dönemlerde yüksek tansiyon, obezite, kassal zayıflık, postürel bozukluk, diyabet gibi risk faktörlerinin artması, göğüs kafesi esnekliği ve solunum kapasitesinde kayıplar, karın kaslarının zayıflaması ile sindirim ve boşaltım güçlükleri, duruş bozukluğu, tüm kaslarda kuvvet, esneklik, dayanıklılık gibi temel motorik özelliklerde işlev kaybı ve kolay sakatlanma, kemik mineral yoğunluğunda kayıplar, eklem kireçlenmesi ve işlevkaybı, kan şekeri ve kan lipid düzeylerinin artması, gıdalar ile alınan enerjinin harcanamaması nedeni ile şişmanlık ve şekilsizlik yanında, şişmanlığın getirdiği bedensel ve ruhsal sorunlar uzun süreli hareketsiz yaşamın organizmadaki olumsuz etkileridir (Çolakoğlu, 2003). Şişman ve obez bireyler sağlıklı bireylerden daha çok düşme, düşme ile ilgili sağlık sorunlarına (Mitchell ve ark, 2014)ve fonksiyonel limitasyona (Vasquez ve ark, 2014) sahiptir. Bu bireylerde sedanter yaşam tarzını azaltarak düzenli ağırlık egzersizleri yapmak düşme riskini azaltabilir (Mitchell ve ark, 2014).

Obezite gelişiminde başlica risk faktörleri; genetik, fiziksel aktivitede azalma, beslenme alışkanlıkları, yaş (yaşlandıkça artar), kadın olmak, evlilik, sigarayı yeni bırakmak ve alkol alımı iken (Nazlıcan ve ark., 2011), toplumlar arasında farklılıklar göstermekle birlikte, düşük öğrenim durumu, bir işte çalışmama, artan gebelik sayısı da obezite için risk faktörleridir. Bazı araştırmalarda, obezite sıklığının diğer iş grubundaki kadınlara göre ev kadınlarında 2 ile 2.5 kat arasında daha fazla bulunduğu belirtilmektedir. Bununla birlikte, bazı endokrin ve psikolojik temelli kronik hastalıklar ve bunların tedavisinde kullanılan ilaçlar da obezite faktörü olarak görülmektedir (Koruk ve Şahin, 2005).

Fiziksel aktivitenin genel popülasyon üzerinde glisemik kontrol, hipertansiyon, dislipidemi, kronik sistemik inflamasyon, obezite, kas yorgunluğu, kardiyovasküler riskleri azaltmak gibi pozitif etkileri içeren bir çok sağlığa yararlı etkileri olduğu bilinir. Bu etkiler koroner kalp hastalıkları, kronik respiratuar hastalıklar, diyabet ve kanseri içeren durumlarda uzun sürede ortaya çıar. Egzersiz programının kullanışlı olabilmesi için uygulanabilir, uygun maliyetli ve sürdürülebilir olması gereklidir. Ayrıca basit, evde de yapılabilen, özel ekipman ve öğrenme gerektirmemelidir. Genel sağlık için en yaygın kabul gören egzersiz formu yürüyüştür (Kosmadakis ve ark., 2012).

Bir fiziksel aktivite olan düzenli yürüyüşün tüm yaş gruplarındaki insanlar için sağlığa yararlı etkileri vardır. Ölüm nedenlerinde azalma, strok ve kalp hastalıkları risk faktörlerinde iyileşme (hipertansiyon, insülin direnci, diyabet, dislipidemi, obezite, fiziksel inaktivite), klinik kardiyovasküler olaylar, depresyon semptomları, osteoartirit, meme ve kolon kanseri görülme sıklığında azalma sağlığa yararları arasındadır. Fiziksel aktivitenin sağlığa yararlarına rağmen akselerometre verilerine dayanarak 40 yaş ve üzeri kadınların \% 10'undan daha azı yeterli aktiviteyi yapmaktadır (orta dereceli fiziksel aktivite, $150 \mathrm{dk} \backslash$ hafta ). Davranışsal, çevresel, sosyal ve biyolojik etmenler kadınların fiziksel aktivitelerini etkileyebilir. Yaş, fiziksel aktivite geçmişi, ırkletnik yapı, eğitim, sosyo-ekonomik düzey de kadınlarda fiziksel aktivite ile ilişkili içsel faktörlerdir. Yaşlı, azınlıkta kalan veya eğitim seviyesi düşük kadınlar, eğitim seviyesi yüksek, beyaz veya genç kadınlarla karşılaştırıldıklarında daha az serbest zaman fiziksel aktivitelerine katılırlar(Perry ve ark., 2014).Yürüyüş, sağlık çalışanları tarafından da tavsiye edilir (Lee et al., 2010; Murphy et al., 2007) ayrıca güvenliği ve uygulanabilirliği açısından yaygın bir şekilde kullanılır (Tudor-Locke ve ark., 2011). 
Bu çalışmanın amacı, Bilecik ilinde şehir merkezinde yaşayıp, rekreatif bir etkinlik olarak yürüyüş aktivitelerine katılan kadınlarda obezite prevalansı ve obeziteyi etkileyen risk faktörlerinin araştırılmasıdır.

\section{YÖNTEM}

\section{Araştırma Grubu}

Çalışmaya Bilecik Şeyh Edebali Stadyumunda rekreasyonel olarak yürüyüş egzersizi yapan, 18-54 yaş arası, 79 kadın dahil edilmiştir (n: 79, yaş ort:36,2 yıl, boy ort: 1,58 cm, BMI ort: 31,68kg \m²). Çalışma gönüllü kadınlarla yapılmıştır.

\section{Veri Toplama Araçları}

Bilecik Şeyh Edebali Stadyumunda dört haftalık gözlemin ardından spora katılımın en yoğun olduğu cumartesi gününde 17:30-20:30 saatleri arasında egzersiz yapan kadınlar, araştırmacılar tarafından sonraki gün toplantıya davet edildi. İkinci gün yapılan toplantıda çalışmayla ilgili bilgiler verildi. Katılımcılar, ölçümlerden 24 saat öncesinde alkol, ilaç, aşırı yağlı yiyecekler tüketmemeleri, yorucu aktivite yapmamaları konusunda uyarıldı. Sonraki hafta cumartesi günü17:30-20:30 saatleri arasında çalışmaya gönüllü olarak katılmak isteyen katılımcılardan imzalı gönüllü onam formları alındıktan sonra detaylı ölçümlerin yapılması için çalışmacılar tarafından stadyumda gönüllülerin boy uzunlukları, vücut ağırlıkları, yağ yüzdeleri, bazal metabolik hızları, bel çevreleri, kalça çevreleri ölçüldü. Tüm katılımcıların spora katılım, obezite prevelansı ve risk faktörlerini belirlemek amacıyla yüz yüze görüşme yöntemi ile epikriz formu doldurmaları sağlandı.

Obezite açısından risk oluşturabileceği düşünülen, mesleki durumu (ev hanımı veya herhangi bir işte çalışan), eğitim düzeyi (okuma yazma bilmeyen- ilkokul mezunu ortaokul mezunulise mezunu-üniversite mezunu), sosyal güvencesi (sosyal sigortalar kurumu-emekli sandı̆̆gbağkur),sigara kullanımı öyküsü (içen - içmeyen), alkol kullanımı öyküsü (içen - içmeyen), gebelik şekli(yok-normal-sezaryen-sezaryen ve normal), doğum sayısı (yok,1,2,3,4 ve üzeri), menstural durum (yok-düzenli adet-düzensiz adet), menopoz durumu (evet-hayır), son altı ayda düzenli spor yapma alışkanlığı(evet-hayır), diyet alışkanlığı(var-yok)gibi değişkenler risk faktörleri olarak değerlendirmeye alındı.

\section{Antropometrik Ölçümler}

Boy uzunluğu ölçümü; gönüllü ayakta dik pozisyonda, çıplak ayak, ayak topukları bitişik, baş dik ve gözler karşıya bakar durumda $0.01 \mathrm{~m}$ hassasiyetinde olan metal stadiometre ile $\mathrm{cm}$ cinsinden ölçülmüştür.

Vücut Ağırlı̆̆ı Ölçümü; gönüllü vücut ağırlığı parametreleri (vücut ağırlığı, vücut yağ yüzdesi, bazal metabolik hız) ölçmek için hassasiyeti $\pm 0.1 \mathrm{~kg}$ olan baskül (BF510, Omron Healthcare Co. 
Ltd., Kyoto, Japan) kullanılmıştır ( Bosy-Westphal ve ark., 2008). Gönüllülerin vücut ağırlıkları; üzerinde $\mathrm{t}$-şört ve şort varken, çıplak ayak ve anatomik duruş pozisyonunda iken 'kg' olarak ölçüldü.

Katılımcıların bel çevresi ölçümleri, deneğin üzerinde t-şört ve şort varken, çıplak ayak ve anatomik duruş pozisyonunda iken arkuskostarum ile processus spinailiaka anterior süperior arasındaki en dar çap mezura kullanılarak ölçüldü, cm olarak belirtildi.

Katılımcıların kalça çevresi ölçümleri, deneğin üzerinde $t$-şört ve şort varken, çıplak ayak ve anatomik duruş pozisyonunda iken gluteus maksimusların en çıkıntılı yerinden ve önde simfizispubis üzerinden geçen en geniş çap gullik şeridi kullanılarak ölçüldü, cm olarak belirtildi.

Bel Kalça Oranı (BKO): Deneğin bel ve kalça çevre ölçümleri alındıktan sonra (WHO, 2008) aşağıdaki şekilde formüle edildi:

$\mathrm{BKO}=($ Bel çevresi $[\mathrm{cm}] /$ Kalça çevresi $[\mathrm{cm}])$

Beden kitle indeksi; vücut ağırlığı ve boy uzunluğu ölçümleri alındıktan (WHO, 2008) sonra aşağıdaki şekilde formüle edildi:

BKİ $=\left(\right.$ Ağırlık $[\mathrm{kg}] /$ Boy $\left.^{2}[\mathrm{~m}]\right)$

Beden Kitle indeksi (BKİ) kategorileri 18.5'in altı “zayıf”, 18.5-24.9 arası "normal”, 25.0-29.9 aras1 "hafif şişman (fazla kilolu)", 30.0-34.9 arası "orta derece şişman (Obez I)", 35.0-39.9 arası "ağır derece şişman (Obez II)", 40’ın üzeri “çok ağır derece şişman (Obez III)” olarak değerlendirildi (WHO, 1997).

\section{Araştırma Modeli}

$\mathrm{Bu}$ araştırma, Bilecik ilinde yaşayıp, Şeyh Edebali Stadyumunda rekreasyonel olarak yürüyüş egzersizi yapan kadınlarda obezite görülme sıklığı ve risk faktörlerini ortaya çıkarmaya yönelik kesitsel bir araştırmadır.Elde edilen veriler bilgisayar ortamına aktarılarak SPSS ("Statistical Package for the Social Sciences") 17,00 paket programı ile aritmetik ortalama, standart sapma yada yüzde olarak gösterilmiştir.

Çalışma başlamadan önce Eskişehir Osmangazi Üniversitesi Tıp Fakültesi Etik Kurulu’ndan etik kurul raporu alınmıştır (2010/137). 


\section{BULGULAR}

Tablo I. Araştırmaya katılan kadınların fiziksel ve fizyolojik parametreleri

\begin{tabular}{lc}
\hline Değişkenler & $\overline{\mathrm{X}} \pm$ ss \\
\hline Yaş (yıl) & $36,2 \pm 10,4$ \\
Boy Uzunluğu(cm) & $1,58 \pm 0,06$ \\
Vücut Ağırlı̆̆ı (kg) & $79,2 \pm 14,61$ \\
BKİ (kg \m²) & $31,68 \pm 6,01$ \\
Bel Çevresi(cm) & $96,13 \pm 10,64$ \\
Kalça Çevresi (cm) & $110,98 \pm 10,21$ \\
Bel - Kalça Oranı & $0,86 \pm 0,04$ \\
Vücut Yağı (\%) & $37,6 \pm 6,47$ \\
Bazal Metabolik Hız (kkal/gün) & $1504 \pm 163,6$ \\
\hline
\end{tabular}

$\overline{\mathrm{X}}$; aritmetik ortalama, ss; standart sapma

Araştırmaya katılan kadınların yaş, boy uzunluğu, vücut ağırlığı, BKİ, bel çevresi, kalça çevresi, bel - kalça oranı, vücut yağ yüzdesi, ve bazal metabolik hız aritmetik ortalama ve standart sapma değerleri tablo 1'de özetlenmiştir.

Tablo 2. Obezitenin eğitim düzeyine göre dağılımı

\begin{tabular}{|c|c|c|c|c|c|c|}
\hline \multirow[t]{3}{*}{ EĞİTİM DÜZEYİ } & \multicolumn{4}{|c|}{ OBEZİTE DURUMU } & \multicolumn{2}{|c|}{ TOPLAM } \\
\hline & \multicolumn{2}{|c|}{ OBEZ } & \multicolumn{2}{|c|}{ OBEZ DEĞİL } & \multirow[b]{2}{*}{$\mathbf{n}$} & \multirow[b]{2}{*}{$\%^{* *}$} \\
\hline & $\mathbf{n}$ & $\%^{*}$ & $\mathbf{n}$ & $\%^{*}$ & & \\
\hline Okuma yazma bilmeyen & 0 & 0 & 0 & 0 & 0 & 0 \\
\hline İlkokul mezunu & 21 & 26,6 & 11 & 13,9 & 32 & 40,5 \\
\hline Ortaokul mezunu & 4 & 5,1 & 3 & 3,8 & 7 & 8,9 \\
\hline Lise Mezunu & 15 & 19,0 & 8 & 10,1 & 23 & 29,1 \\
\hline Üniversite Mezunu & 9 & 11,4 & 8 & 10,1 & 17 & 21,5 \\
\hline TOPLAM & 49 & 62,0 & 30 & 38,0 & 79 & 100 \\
\hline
\end{tabular}

*Satır yüzdesi ${ }^{* *}$ Sütun yüzdesi

Obezitenin eğitim düzeyine göre dağılımı incelendiğinde; kadınların 32'si (\%40,5) ilkokul mezunu, 7'si ortaokul mezunu (\%8,9), 23'ü lise mezunu (\%29,1), 17'si üniversite mezunudur (\% 21,5). Obezitenin en sık ilkokul mezunlarında \% 26,6 olduğu, eğitim düzeyi arttıkça obezitenin azaldı̆̆ı görülmektedir (Tablo 2). 
Tablo 3. Obezitenin mesleki durum ve sosyal güvenceye göre dağılımı

\begin{tabular}{|c|c|c|c|c|c|c|}
\hline \multirow{3}{*}{ MESLEKİ DURUM } & \multicolumn{4}{|c|}{ OBEZITE DURUMU } & \multicolumn{2}{|c|}{ TOPLAM } \\
\hline & \multicolumn{2}{|c|}{ OBEZ } & \multicolumn{2}{|c|}{ OBEZ DEĞİL } & & \\
\hline & $\mathbf{n}$ & $\%^{*}$ & n & $\%^{*}$ & $\underline{n}$ & $\%^{* *}$ \\
\hline Ev hanımı & 32 & 40,5 & 24 & 30,4 & 56 & 70,9 \\
\hline Çalışan & 17 & 21,5 & 6 & 7,6 & 23 & 29,1 \\
\hline TOPLAM & 49 & 62 & 30 & 38 & 79 & 100 \\
\hline \multirow{3}{*}{ SOSYAL GÜVENCE } & \multicolumn{4}{|c|}{ OBEZITTE DURUMU } & \multirow{2}{*}{\multicolumn{2}{|c|}{ TOPLAM }} \\
\hline & \multicolumn{2}{|c|}{ OBEZ } & \multicolumn{2}{|c|}{ OBEZ DEĞİL } & & \\
\hline & $\mathbf{n}$ & $\%^{*}$ & $\underline{\mathbf{n}}$ & $\%^{*}$ & n & $\%^{* *}$ \\
\hline SSK & 31 & 39,2 & 20 & 25,3 & 51 & 64,6 \\
\hline Emekli Sandığı & 16 & 20,3 & 8 & 10,1 & 24 & 30,4 \\
\hline Bağkur & 2 & 2,5 & 2 & 2,5 & 4 & 5,1 \\
\hline TOPLAM & 49 & 62 & 30 & 38 & 79 & 100 \\
\hline
\end{tabular}

${ }^{*}$ Satır yüzdesi ${ }^{* *}$ Sütun yüzdesi

Obezitenin mesleki durum ve sosyal güvenceye göre dağılımı incelendiğinde; kadınların 56’sının ev hanımı olduğu (\% 70,9), 23 'ünün ise herhangi bir işte çalıştı̆̆ $1(\% 29,1)$, obez olan ve olmayan kadınların tamamının ise herhangi bir sosyal güvencesi olduğu SSK(\%64,6), Emekli sandı̆̆ı (\% 30,4), Bağkur $(\% 5,1)$ görülmektedir. Obezite görülme sıklığının ev hanımlarında \%40,5 olduğu ve çalışan kadınlarda bu sıklığın azaldığı bulunmuştur. (Tablo 3).

Tablo 4. Obezitenin sigara ve alkol alışkanlığına göre dağılımı

\begin{tabular}{|c|c|c|c|c|c|c|}
\hline \multirow{3}{*}{ SİGARA ALIŞKANLIĞI } & \multicolumn{4}{|c|}{ OBEZITE DURUMU } & \multirow{2}{*}{\multicolumn{2}{|c|}{ TOPLAM }} \\
\hline & \multicolumn{2}{|c|}{ OBEZ } & \multicolumn{2}{|c|}{ OBEZ DEĞİL } & & \\
\hline & n & $\%^{*}$ & n & $\%^{*}$ & $\mathbf{n}$ & $\%^{* *}$ \\
\hline Olan & 8 & 10,1 & 7 & 8,9 & 15 & 19 \\
\hline Olmayan & 41 & 51,9 & 23 & 29,1 & 64 & 81 \\
\hline TOPLAM & 49 & 62 & 30 & 38 & 79 & 100 \\
\hline \multirow{2}{*}{ ALKOL ALIŞKANLIĞI } & \multicolumn{4}{|c|}{ OBEZITE DURUMU } & \multicolumn{2}{|c|}{ TOPLAM } \\
\hline & n & $\%^{*}$ & & $\begin{array}{c}\text { ĞİL } \\
\%^{*} \\
\end{array}$ & $\underline{\mathbf{n}}$ & $\%^{* *}$ \\
\hline Olan & 0 & 0 & 2 & 2,5 & 2 & 2,5 \\
\hline Olmayan & 49 & 62 & 28 & 35,4 & 77 & 97,5 \\
\hline TOPLAM & 49 & 62 & 30 & 38 & 79 & 100 \\
\hline
\end{tabular}

${ }^{\star}$ Satır yüzdesi ${ }^{* *}$ Sütun yüzdesi

Obezitenin sigara ve alkol alışkanlığına göre dağılımı incelendiğinde; kadınların çoğunluğunun (\% 81) sigara tüketmediği, obez kadınların ise \%51,9’unun sigara alışkanlığı olmadığı ve yine büyük çoğunluğun $(\% 97,5)$ alkol tüketmediği bu oranın obez kadınlarda \%62 olduğu görülmektedir (Tablo 4). 
Tablo 5. Obezitenin spor ve diyet alışkanlığına göre dağılımı

\begin{tabular}{|c|c|c|c|c|c|c|}
\hline \multirow{3}{*}{ SPOR ALIŞKANLIĞI } & \multicolumn{4}{|c|}{ OBEZITTE DURUMU } & \multirow{2}{*}{\multicolumn{2}{|c|}{ TOPLAM }} \\
\hline & \multicolumn{2}{|c|}{ OBEZ } & \multicolumn{2}{|c|}{ OBEZ DEĞİL } & & \\
\hline & n & $\%^{*}$ & $\mathbf{n}$ & $\%^{*}$ & $n$ & $\%^{\star *}$ \\
\hline Olan & 6 & 7,6 & 6 & 7,6 & 12 & 15,2 \\
\hline Olmayan & 43 & 54,4 & 24 & 30,4 & 67 & 84,8 \\
\hline TOPLAM & 49 & 62 & 30 & 38 & 79 & 100 \\
\hline \multirow{3}{*}{ DİYET ALIŞKANLIĞI } & \multicolumn{4}{|c|}{ OBEZİTE DURUMU } & \multirow{2}{*}{\multicolumn{2}{|c|}{ TOPLAM }} \\
\hline & \multicolumn{2}{|c|}{ OBEZ } & \multicolumn{2}{|c|}{ OBEZ DEĞİL } & & \\
\hline & n & $\%^{*}$ & $\mathbf{n}$ & $\%^{*}$ & $\mathbf{n}$ & $\%^{* *}$ \\
\hline Olan & 1 & 1,3 & 3 & 3,8 & 4 & 5,1 \\
\hline Olmayan & 48 & 60,8 & 27 & 34,2 & 75 & 94,9 \\
\hline TOPLAM & 49 & 62 & 30 & 38 & 79 & 100 \\
\hline
\end{tabular}

*Satır yüzdesi ${ }^{*}$ Sütun yüzdesi

Obezitenin spor ve diyet alı̧skanlığına göre dağılımı incelendiğinde; kadınların \% 84,8’inin spor yapma alışkanlığının olmadığı, bu oranın obez kadınlarda (\% 54,4) olduğu, yine diyet yapma alışkanlıklarının \% 94'ünde olmadığı, yine obezlerde bu oranın \% 60,8 olduğu görülmektedir (Tablo 5).

Tablo 6. Obezitenin doğum şekli ve doğum sayısına göre dağııımı

\begin{tabular}{|c|c|c|c|c|c|c|}
\hline \multirow{3}{*}{ GEBELİK ŞEKLİ } & \multicolumn{4}{|c|}{ OBEZITTE DURUMU } & \multirow{2}{*}{\multicolumn{2}{|c|}{ TOPLAM }} \\
\hline & \multicolumn{2}{|c|}{ OBEZ } & \multicolumn{2}{|c|}{ OBEZ DEĞİL } & & \\
\hline & $\mathbf{n}$ & $\%^{*}$ & n & $\%^{\star}$ & $\mathbf{n}$ & $\%^{\star *}$ \\
\hline Yok & 9 & 11,4 & 12 & 15,2 & 21 & 26,6 \\
\hline Normal & 28 & 35,4 & 13 & 16,5 & 41 & 51,9 \\
\hline Sezaryen & 9 & 11,4 & 2 & 2,5 & 11 & 13,9 \\
\hline Normal ve sezaryen & 3 & 3,8 & 3 & 3,8 & 6 & 7,6 \\
\hline TOPLAM & 49 & 62 & 30 & 38 & 79 & 100 \\
\hline \multirow{2}{*}{ GEBELIKK SAYISI } & \multicolumn{4}{|c|}{ OBEZITTE DURUMU } & \multicolumn{2}{|c|}{ TOPLAM } \\
\hline & $\mathbf{n}$ & & $\underset{\mathbf{n}}{\mathbf{O}}$ & $\begin{array}{l}\text { ĞİL } \\
\text { \% }^{*}\end{array}$ & $\mathbf{n}$ & $\%^{* *}$ \\
\hline Yok & 9 & 11,4 & 12 & 15,2 & 21 & 26,6 \\
\hline Bir & 6 & 7,6 & 2 & 2,5 & 8 & 10,1 \\
\hline İki & 28 & 35,4 & 12 & 15,2 & 40 & 50,6 \\
\hline Üç & 5 & 6,3 & 3 & 3,8 & 8 & 10,1 \\
\hline Dört ve üzeri & 1 & 1,3 & 1 & 1,3 & 2 & 2,5 \\
\hline TOPLAM & 49 & 62 & 30 & 38 & 79 & 100 \\
\hline
\end{tabular}

${ }^{\star}$ Satır yüzdesi ${ }^{*}$ Sütun yüzdesi 
Obezitenin gebelik şekli ve gebelik sayısına göre dağılımı incelendiğinde; obez kadınların da(\% $35,4)$, obez olmayan kadınların da(\%16,5) normal doğumu tercih ettikleri, ayrıca \% 35.4’ünün iki kez doğum yaptı̆̆ı $(\mathrm{n}=28)$ görülmektedir (Tablo 6).

Tablo 7. Obezitenin menstural ve menopoz durumuna göre dağılımı

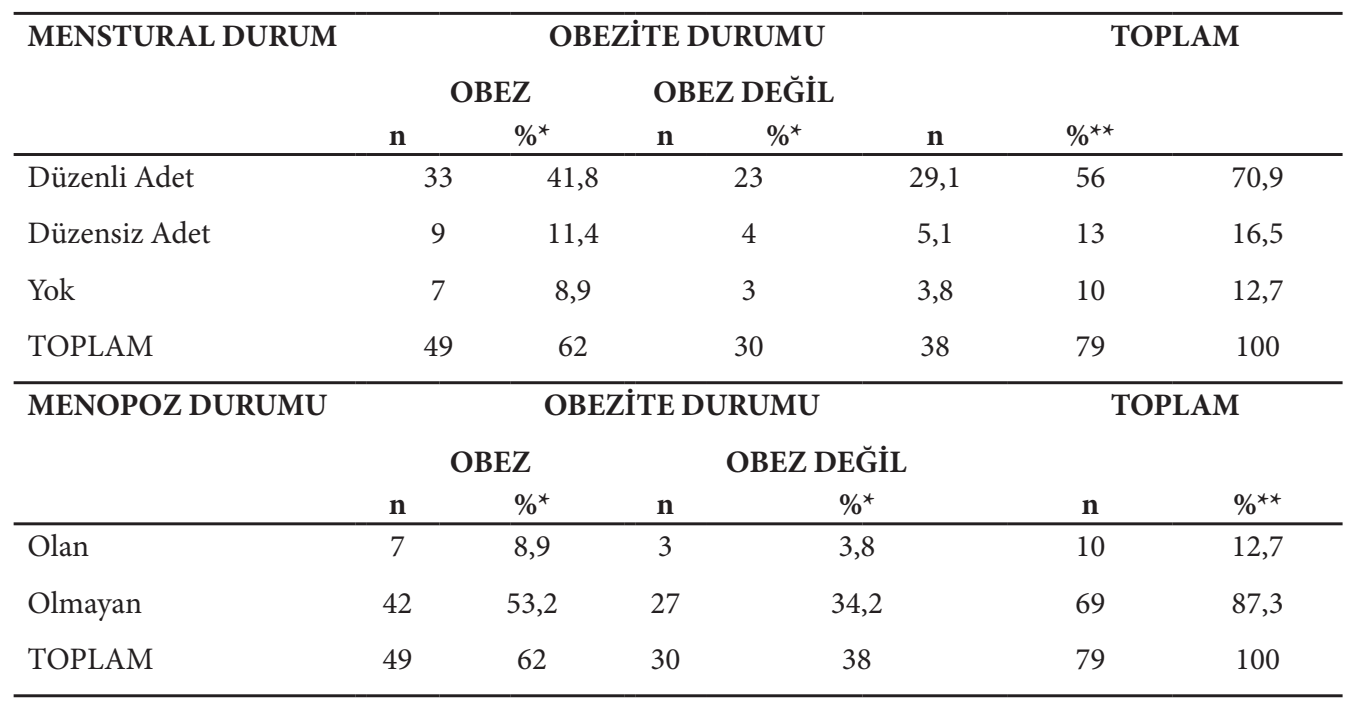

${ }^{\star}$ Satır yüzdesi ${ }^{*}$ Sütun yüzdesi

Obezitenin menstural ve menopoz durumuna göre dağılımı incelendiğinde; obez kadınların $\%$ 41,8'inin düzenli adet olduğu $(\mathrm{n}=33)$ ayrıca \% 53,2'sinin menopoza girmedikleri $(\mathrm{n}=42)$ görülmektedir (Tablo 7).

\section{TARTIŞMA}

Bu çalışmada, Bilecik ilinde şehir merkezinde yaşayıp, rekreatif bir etkinlik olarak yürüyüş aktivitelerine katılan kadınlarda obezite prevalansı ve obeziteyi etkileyen risk faktörleri araştırılmıştır.

Çalışmamızda obezite prevalansı \% 62 bulunmuştur. Ülkemizde yapılan diğer çalışmalarda; Bigadiç’te \% 25.6 (Selçuk ve Ünal. 2013), Düzce’de \%53.1 (Aydın ve ark. 2012), Ankara \% 35.1 (Çayır ve ark. 2011), Tokat'ta \%33.6 (Kutlutürk ve ark. 2010), Afyonkarahisar'da \%39.8 (Doğan ve ark. 2010), Elazı̆̆’da \% 64.9 (Arslan ve Ceviz. 2007), İzmir’de 50.8 (Okyay ve Uçku. 2002), Konyada \% 33.9 (Koruk ve Şahin. 2005), Adana ilinde yaşayan 20-64 yaş arası kadınlarda \%28.3,20 yaş ve üstü yetişkinlerde yapılan TURDEP çalışmasında obezite prevalansı kadınlarda \% 29.9, TOHTA çalışmasında ise \%36 olarak bulunmuştur.(Nazlıcan ve ark. 2011). Yapılan çalışmalara göre ülkemizde obezite prevalansı farklı sonuçlar vermektedir. Bu farklılıklar, bölge 
farklılığı, gelenekler, beslenme alışkanlığı, iklim, örneklemin seçim yöntemi gibi sebeplerden kaynaklandığı düşünülebilir. Fakat elde edilen sonuçta obezite görülme sıklığı oldukça yüksek bir değerdedir.

Eğitim düzeyi ile obezite görülme sıklı̆ğı karşılaştırıldığında; obezitenin en sık ilkokul mezunlarında \% 26,6 olduğu, eğitim düzeyi arttıkça da obezitenin azaldığı görülmektedir. Bulgularımız literatürle benzerlik göstermektedir (Çetin ve ark. 2012; Nazlıcan ve ark. 2011; Çayır ve ark. 2011; Doğan ve ark. 2010; Arslan ve Ceviz. 2007; Koruk ve Şahin. 2005; Akman ve ark. 2004; Okyay ve Uçku. 2002; Haijan-Tilaki ve Heidari, 2007). Bireylerin eğitim düzeylerinin artması ile diyet yani seçerek yeme bilgi-becerilerinin arttığı düşünülebilir. Ayrıca, kültürümüze göre aile içerisinde beslenmeyi kadınların yönlendirdiği göz önüne alındığında gelecek açısından diğer aile fertleri ve toplum düşünüldügünude konu daha da önem kazanmaktadır.

Obezitenin mesleki durum ve sosyal güvenceye göre dağılımı incelendiğinde; obezite görülme sıklığının ev hanımlarında $\% 40,5$ olduğu ve çalışan kadınlarda bu sıklığın azaldığı bulunmuştur. Literatürle benzerlik gösteren sonuçların (Aydın ve ark. 2012, Çayır ve ark. 2011, Arslan ve Ceviz. 2007, Okyay ve Uçku. 2002) sosyal hayata aktif katılan çalışan kadınların çalışma şartları, sosyal sorumluluk ve dış görünümlerine verdikleri önemden ayrıca da bu durum gelir düzeyi ile de ilişkilendirildiğinde protein alımının azalması, karbonhidrat tüketiminin artmasından kaynaklandığı şeklinde düşünülebilir.

Obezitenin sigara ve alkol alı̧̧kanlığına göre dağılımı incelendiğinde; obez kadınların $\% 51,9$ ’unun sigara ve \% 62'sinin alkol alışkanlığı olmadığı görülmektedir. Obezite gelişimindeki başlıca risk faktörlerinden ikisi sigarayı yeni bırakmak ve alkol tüketimi iken literatürde farklı sonuçlar mevcuttur. Bazı çalışmalarda obezite ile sigara (Kutlutürk ve ark. 2011, Nazlıcan ve ark. 2011, Doğan ve ark. 2010, Aydın ve ark. 2012, Çayır ve ark. 2011, Selçuk ve Ünal. 2013, Okyay ve Uçku. 2002) ve alkol (Çayır ve ark. 2011, Kutlutürk ve ark. 2011, Okyay ve Uçku. 2002, Koruk ve Şahin. 2005) tüketimi arasında ilişki bulunmadığını beyan etmektedirler. Türkiye de sigara içmenin yüksek olduğu ülkeler arasındadır. Küresel Yetişkin Tütün Araştırması’na göre (KYTA) sigara içme sıklığı (her gün ve ara sıra kullanan) kadınlarda \%15.2 (Doğanay ve ark., 2012), TEKHARF çalışmasına göre ise \% 15'dir (Aydın, 2006). Çalışmamızda obez kadınların $\% 10,1^{\prime} \mathrm{i}$, obez olmayan kadınların \% 8,9'u toplamda ise kadınların \% $19^{\prime} \mathrm{u}$ sigara tükettiğini beyan ederek dünya aslında yüksek bir oranda bulunduklarını ortaya çıkartmışlardır. Yapılan bir araştırmada, ülkemizde yapılan çalışmalarda alkol kullanımıyla obezite arasında ilişki olmadığı alkol kullanımının sadece artmış BKİ ile ilişkili değil aynı zamanda bozulmuş açlık glikozu gibi birçok metabolik risk faktörüyle ilişkili olduğu bildirilmiştir (Kutlutürk ve ark. 2011).

Obezitenin spor ve diyet alışkanlığına göre dağılımı incelendiğinde; obez kadınların \%54,4'ünün spor ve \% 60,8'inin diyet alışkanlığı olmadığı görülmektedir. Obez olmayanlarda da bu rakamlar neredeyse yarı yarıya(\% 30,4 ve \% 34,2) değerine ulaşarak risk sınırına yaklaşmaktadırlar. TEKHARF çalışması sonuçlarına göre kadınlarda fizik aktivite düzeyi her yaş grubunda erkeklerden daha düşük bulunmaktadır. Sedanter olma oranı 1990 yılı verilerine göre 2029 yaş grubundan 70 yaş ve üzeri gruba gidildiğinde kadınlarda $\% 3$ 'ten $\% 52$ 'ye kadar 
çıkmaktadır(Aydın, 2006). Ev hanımı ve çalışan kadınlarla ilgili yapılan bir çalışmada, çalışan kadınların egzersiz alışkanlığı ve beslenme alışkanlığı bakımından ev hanımlarına göre daha iyi durumda olduğu ayrıca, obezite limiti aşıldıktan sonra fiziksel aktivite alışkanlıklarında giderek artan bir azalma meydana geldiği gözlendi. Çalışma sonuçlarına göre sağlıklı yaşam biçimi davranışları ve egzersiz alışkanlığı arttıkça obezite prevalansının düştüğü anlaşılmaktadır (Arslan ve Ceviz, 2007). Yapılan bir başka çalışmada da araştırmaya katılan kadınlardan ancak \% 4.5'inin düzenli bir egzersiz alışkanlığı saptanmıştır (Okyay ve Uçku, 2002). Diğer çalışmalarda kadınların \% 66.4'ünün(Koruk ve Şahin. 2005), \%85.82' inin (Genç ve ark. 2002), \% 88’inin (Yurdakul ve ark, 2007) egzersiz yapmadığı tespit edilmiştir. Literatürde kilolu ve obez kişilerde en iyi sonuç veren uygulamanın düşük kalorili diyet, fiziksel aktivitenin artırılması ve davranış terapisini içeren kombine bir tedavi olduğu önerilmektedir (Baltacı, 2012). Yapılan çalışmalarda düzenli egzersizin yaşam kalitesini(Yurdakul ve ark, 2007), vücut ağırlıklarını, vücut kitle indeksini, istirahat kalp atım sayısını, aerobik ve anaerobik gücü, esneklik değerlerini (Karacan ve ark, 2004) olumlu yönde etkilediği belirtilmektedir. Yunanistan’da yapılan bir çalışmada, kadınlarda haftada dört saatten az spor yapmanın şişmanlıkla ilişkili olduğu bulunmuştur (Hassapidou ve ark, 2013). Çin'de yapılan bir çalışmada ise fiziksel aktivite sayısının azalması ile şişmanlık ve obezite prevalansı arasında yüksek ilişki olduğu belirtilmektedir (Tian ve ark, 2014).

Gebeliksayısı ve doğum şekli ile obezite görülme sıklığı karşılaştırıldığında obez kadınların \% 35.4’ünün iki kez doğum yaptığı, ayrıca \% 35,4’ünün de normal doğum yaptıkları görülmektedir. Literatürde gebelik sayısı ile obezite sıklığı arasında anlamlı derecede ilişki olduğunu belirten çalışmalar mevcuttur (Nazlıcan ve ark., 2011; Arslan ve Ceviz, 2007; Aydın ve ark., 2012). Yapılan bir çalışmada hiç çocuğu olmayanların \%12.6'sı, 1 çocuğu olanların \%32.6'sı, 2 çocuğu olanların \%32.5’i, 3 ve daha fazla çocuğu olanların \%48.2'si obez bulunmuştur (Çayır ve ark., 2011). Literatürdeki diğer çalışmalara baktığımızda ise obezitedeki risk faktörünün gebelik sayısının üç ve üzerinde (Güneş ve ark., 2000), 3-4 arasında (Koruk ve Şahin, 2005), dört ve üzerinde (Okyay ve Uçku, 2002), 5 ve üzerinde (Doğan ve ark., 2010; Koruk ve Şahin, 2005) doğum yapma ile arttığı bulunmuştur. Doğurganlık ve vücut ağırlığı ilişkisinin gerçekte sosyal ve davranışsal faktörlerden etkilendiği ileri sürülmektedir (Arslan ve Ceviz, 2007). Toplumumuzda gebelik sayısı arttıkça yaş da artmaktadır oysa fiziksel aktivitede azalma olduğu unutulmamalıdır.

Çalışmamızda obezitenin menstural ve menopoz durumuna göre dağılımı incelendiğinde, yürüyüş egzersizlerine katılan kadınların \% 62'sinin obez ( $n=49)$, \% 38'inin obez olmadığ 1 (n=38) görülmektedir. Obez kadınların \% 41.8’i düzenli adet, \% 11.4〉ü düzensiz adet görmektedir. Ayrıca obez kadınların \% 8.9'u menopozda olup, \% 53.2'si menopozda değildir.Yapılan araştırmalarda menopozda olan kadınlarda obezite prevelansı \%64 (Aydın ve ark., 2012), \%41.0 (Çayır ve ark., 2011) iken, menapozda olmayan kadınlarda bu oran \%43 (Aydın ve ark., 2012) ve \%29.7 (Çayır ve ark., 2011) olarak saptanmıştır. Bir başka çalışmada ise çalışmaya katılan kadınların \%62.3’ü menopozda olup, bunların \%83.3'ünün kendiliğinden menopoza girdiği bildirilmiştir (Aydın ve ark., 2012). 


\section{SONUÇ}

Sonuç olarak, Bilecik ilinde şehir merkezinde yaşayıp, rekreatif bir etkinlik olarak yürüyüş aktivitelerine katılan kadınlarda obezite görülme sıklığının yüksek (\% 62) olduğu, eğitim düzeyi arttıkça obezitenin azaldığı görülmektedir. Eğitim seviyesine göre ilkokul mezunu $(\% 26,6)$ ve ev hanımlarında (\% 40,5) daha sık obeziteye rastlanılmaktadır. Spor yapma alışkanlığı olmayan (\% $7,6)$ obezlerin diyet alışkanlığı da olmadığı $(\% 60,8)$ görülmektedir. Normal doğum yapan obez kadınlarda ve gebelik sayısı iki olanlarda daha yüksek değerlerde obeziteye (\% 35,4) saptanmıştır. Ayrıca büyük çoğunluğun düzenli adet olduğu (\% 41,8) ve menopozda olmadıkları $(\% 53,2)$ saptanmıştır. 


\section{KAYNAKLAR}

Akman M, Budak Ş, Kendir M. (2004).: Genel Dahiliye Polikliniğine Başvuran Hastalarda Obezite Sıklığı ve İlişkili Sağlık Problemleri. Marmara MedicalJournal;17(3);113-120

Anton, Manini TM, Milsom VA, Dubyak P, Cesari M, Cheng J, Daniels, MJ, Marsiske M, Pahor M, Leeuwenburgh C. (2011): Effects of a WeightLoss Plus Exercise Program on Physical Function in Overweight, Olderwomen: a Randomized Controlled Trial. Clinical Interventions in Aging.; Volume: 6: 141-149.

Arslan C, Ceviz D. (2007). Ev Hanımı ve Çalışan Kadınların Obezite Prevalansı ve Sağlıklı Yaşam Biçimi Davranışlarının Değerlendirilmesi. F.Ü. Sağ. Bil. Derg. : 21 (5): 211 - 220.

Aydın P, Günay T, Baydur H, Şimşek H. (2012). :İzmir'de Yarı Kentsel Bir Bölgede 45-59 Yaş Kadınlarda Yaşam Kalitesinin Değerlendirilmesi. Tip Araştırmaları Dergisi.; 10 (3): 88-93.

Aydın Y, Celbek G, Kutlucan A, Önder E, Güngör A, Alemdar R, Coşkun H, Özhan H. (2012) Batı Karadeniz Bölgesinde Obezite Prevelansı: Melen Çalışması. Turk Jem,; 16: 52-7.

Aydın Z D. (2006). Toplum ve Birey İçin Sağlıklı Yaşlanma: Yaşam Biçiminin Rolü. S.D.Ü. Tip Fak. Derg.;13(4):43-48

Baltacı G. Obezite ve Egzersiz. Sağlık Bakanlığı Yayın No: 730; $12-15$.

Black NC. (2014). An Ecological Approach to Understanding Adult Obesity Prevalence in the United States: A County-level Analysis using Geographically Weighted Regression. Applied Spatial Analysis and Policy:; 7(3): 283-299.

Bosy-Westphal A, Later W, Hitze B, Sato T, Kossel E, et al. (2008) Accuracy of Bioelectrical Impedance Consumer Devices for Measurement of Body Composition in Comparison to Whole Body Magnetic Resonance Imaging and Dual X-Ray Absorptiometry. Obes Facts; 1:319-324.

Çayır A, Atak N, Köse SK. (2011). Beslenme ve Diyet Kliniğine Başvuranlarda Obezite Durumu ve Etkili Faktörlerin Belirlenmesi. Ankara Üniversitesi Tip Fakültesi Mecmuası.; 64(1): 13-19.

Çetin F, Güneş G, Özer A. (2012), Malatya İl Merkezinde Yaşayan Kadınlarda Metabolik Sendrom Prevalansı ve Öfke ve Sosyodemografik Özellikler ile İlişkisi: Enine-kesitsel Gözlemsel Bir Araştırma. Anadolu Kard. Derg.12: 53-9.

Çolakoğlu F. (2003). 8 Haftalık Koş- Yürü Egzersizinin Sedanter Orta Yaşlı Obez Bayanlarda Fizyolojik, Motorik ve Somatotip Değerleri Üzerine Etkisi. Gazi Eğitim Fakültesi Dergisi,23( 3): 275-290.

Doğan N, Toprak D, Demir S. (2011). Afyonkarahisar İlinde Obezite Prevalansı ve İlgili Risk Faktörleri. Türkiye Klinikleri J MedSci.31(1):122-32.

Doğanay S, Sözmen K, Kalaça S, Ünal B. (2012). Türkiye’de Toplumda Sigara İçme Sıklı̆̆ı Nasıl Değişiyor? Türkiyede Kalp Damar Hastalıkları ve Diyabet Kontrolünde Var Olan Durum ve Politika Önerileri.:13-25

Genç M, Eğri M, Kurçer MA, Kaya M, Pehlivan E, Karaoğlu L, Güneş G. (2002). Malatya Kent Merkezindeki Banka Çalışanlarında Fizik Aktivite Sıklı̆̆ı. İnönü Üniversitesi Tıp Fakültesi Dergisi. 9(4): 237-240.

Güneș G, Genç M, Pehlivan E. (2000). Yeşilyurt Sağlık Ocağı Bölgesindeki Erişkin Kadınlarda Obezite. Turgut Özal Tip Merkezi Dergisi. 7(1):48-53.

Hajian-Tilaki KO, Heidari B.(2007). Prevalence of Obesity, Central Obesity and the Associated Factors in Urban Population Aged 20-70 Years, in the North of Iran:a Population-Based Study and Regression Approach. Obes Rev.8(1):3-10.

Hassapidou M, Papadopoulou SK, Vlahavas G,Kapantais E, Kaklamanou D, Pagkalos I, Kaklamanou M, Tzotzas T. (2013). Association of physical activity and sedentary life style patterns with obesity and cardiometabolic comorbidities in Greekadults: Data from the National Epidemiological Survey. Hormones-international Journal of Endocrinology and Metabolism. Volume: 12(2): 265-274.

Karacan S, Çolakoğlu FF, Erol AE. (2004). The Effects of Aerobic Exercise in Some Physical Fitness Parameters in Obese Middle Aged Women and Menopausal Women. E.U.Journal of Health Sciences. 13(1): 35-42. 
Kitiş Y, Bilgili N, Hisar F, Ayaz S. (2010). Yirmi Yaş ve Üzeri Kadınlarda Metabolik Sendrom Sıklı̆̆ı ve Bunu Etkileyen Faktörler. Anadolu Kardiyol Derg.; 10: 111-9.

Koruk İ, Şahin TK. (2005). Konya Fazilet Uluışık Sağlık Ocağı Bölgesinde 15-49 Yaş Grubu Ev Kadınlarında Obezite Prevalansı ve Risk Faktörleri. Genel Tip Derg, 15(4):147-155.

Kosmadakis GC, John SG,Clapp EL, Viana JL, Smith AC, Bishop NC, Bevington A, Owen PJ, McIntyre CW, Feehally J. (2012), Benefits of Regular Walking Exercise in Advanced Pre-Dialysis Chronic Kidney Disease. Nephrol Dial Transplant, 27: 997-1004

Kutlutürk F, Öztürk B,Yıldırım B, Özuğurlu F, Çetin İ, Etikan İ, Sazlıdere H, Tetikçok R, Akbaș A, Şahin I. (2011). Obezite Prevalansı ve Metabolik Risk Faktorleri ile İlișkisi: Tokat İli Prevalans Çalışması. Türkiye Klinikleri J MedSci.31(1):156-63.

Lee LL, Watson MC, Mulvaney CA, Tsai CC, Lo SF.(2010). The Effect of Walking Intervention on Blood Pressure Control: A Systematic Review. International Journal of Nursing Studies, 47: 1545-1561.

Mitchell RJ, Lord SR, Harvey LA, Close JCT. (2014). Associations Between Obesity and Owerweight and Fall Risk, Health Status and Quality of Life in Older People. Australian and New Zeland Journal of Public Health. 38(1):13-18.

Murphy MH, Nevill AM, Murtagh EM, Holder RL. (2007). TheEffect of Walking on Fitness, Fatness and Resting Blood Pressure: A Meta-Analysis of Randomised, Controlled Trials. Preventive Medicine, 44: 377-385.

Nazlıcan E, Demirhindi H, Akbaba M. (2011). Adana İli Solaklı ve Karataş Merkez Sağlık Ocağı Bölgesinde Yaşayan 20-64 Yaş Arası Kadınlarda Obezite ve İlişkili Risk Faktörlerinin İncelenmesi. Düzce Üniversitesi Sağllk Bilimleri Enstitüsü Dergisi; 1(2): 5-12.

Okyay P, Uçku R. (2002). İzmirde Kentsel Bir Bölgedeki Doğurgan Çağdaki Kadınlarda Şişmanlık Prevalansı ve Risk Faktörleri. ADÜ Tip Fakültesi Dergisi. 3(3): 5-12.

Perry CK, Herting JR, Berke EM, Nguyen HQ, Moudon AV, Beresford SAA, Ockene JK, Manson JE, LaCroix AZ. (2013). Does Neighborhood Walkability Moderate the Effects of Intrapersonal Characteristics on Amount of Walking in Post-Menopausal Women? Health\&Place, 21: 39-45

Selçuk KT, Ünal B. (2013). Bigadiç’te 45-74 Yaş Bireylerde Diyabet Prevalansı ve Farkındalık Durumunun Belirleyicileri. Turk J Public Health. 11(3): 160-173.

Shields M, Carroll MD, Ogden CL. (2011). Adult Obesity Prevalence in Canada and the United States. NCHS Data Brief. No. 56: 1-8.

Tian XY, Zhao GM, Li YH, Wang L, Shi Y. (2014). Owerweight and Obesity Difference of Chinese Population Between Different Urbanization Levels Journal of Rural Health. 30 (1):101-112.

Tudor-Locke C, Craig CL, Aoyagi Y, Bell RC. Croteau KA. Bourdeaudhuij I, Ewald B, Gardner AW, Hatano Y, Lutes LD, Matsudo SM, Ramirez-Marrero F A, Rogers LQ, Rowe DA, Schmidt MD, Tully MA, Blair SN. (2011). How ManySteps/dayareEnough? For Older Adults and Special Populations. International Journal of Behavioral Nutrition and Physical Activity;;:80.

Vasquez E, Batsis JA, Germain CM, Shaw BA. (2014). Impact of Obesity and Physical Activity on Functional Outcomes in the Elderly: Data From NHANES 2005-2010. Journal of Aging and Health. 26(6): 1032-1046.

WHO Expert Consultation (2008). Waist Circumference and Waist-Hip Ratio: 8-11 December; Geneva, Switzerland.

World Health Organization. (1997). Obesity: Preventing and Managing the Global Epidemic. Report of a WHO Consultation Presented at: the World Health Organization; June 3-5, Geneva, Switzerland. Publication WHO/NUT/NCD/98.1.

Yurdakul M, Eker A, Kaya D. (2007). Menopozal Dönemdeki Kadınların Yaşam Kalitesinin Değerlendirilmesi. F.Ü. Sağ. Bil. Derg. 21 (5): 187 - 193. 